\title{
Application of nanomaterials to enhance microstructure and mechanical properties of concrete
}

\author{
Manish A Kewalramani ${ }^{1 *}$ and Z I Syed ${ }^{1}$ \\ ${ }^{1}$ Department of Civil Engineering \\ Abu Dhabi University, Abu Dhabi, UAE.
}

Received 01 January 2018; accepted 15 April 2018, available online 07 May 2018

\begin{abstract}
The advances of sustainable construction and the green building movement of the past decade have encouraged comprehensive assessment of building materials and construction practices worldwide. With superior fire resistance, strength, and a long service life, concrete is the most widely used construction material in the world. Considering the amount of concrete required for various construction works, enhancing sustainability to concrete, both in terms of concrete production and mix design would be a highly desirable prospect. Lately, nanotechnology is a promising field in terms of environmental improvements including energy savings and reduced reliance on non-renewable resources, as well as reduced waste, toxicity and carbon emissions. Nanotechnology allows enhancement of available concrete products by using nano-materials; these nano-materials could be in the form of nano-particles, nano-chemical additives, and nano-fibers in cement-based materials matrix. The usage of nanomaterials results in production of concrete with lower volume of cement. The influence of addition of various nano particles such as nano silica, nano $\mathrm{Al}_{2} \mathrm{O}_{3}$, nano $\mathrm{TiO}_{2}$, nano $\mathrm{Fe}_{2} \mathrm{O}_{3}$, nano clays, and highly dispersed carbon nano tubes in concrete is thoroughly investigated in present work with an initiative towards 'Green Concrete' incorporating these waste materials as one of its ingredients.
\end{abstract}

Keywords: Nanomaterials, green concrete, carbon nanotubes,

\section{Introduction}

Construction industry is enormous with huge environmental $\mathrm{CO}_{2}$ footprint along with transportation and agricultural industry due to very high greenhouse gas emissions annually. Growing population worldwide, increasing industrialization with ever-increasing energy demands and high urbanization releasing huge volume of greenhouse gases especially carbon dioxide $\left(\mathrm{CO}_{2}\right)$ has resulted in unprecedented problems. Remedial measures need to be taken urgently before catastrophic consequences are observed. Neglectful usage of fossil fuels (or natural resources) is another concern to environmental conservation as it results in huge amounts of waste products with limited reliable and safe methods of disposal or recycling of this waste. Cement industry is single industry responsible for about $5 \%$ of $\mathrm{CO}_{2}$ emissions globally. This industry produces an important construction material - cement whose annual production is continuously growing by $2.5 \%$. Cement is a necessary ingredient in concrete, while concrete is second most consumed substance on earth. On an average proportion of concrete production each year for every person is three tons [1]. The manufacturing of one ton of cement releases almost $700 \mathrm{~kg}$ of $\mathrm{CO}_{2}$ into atmosphere. Hence, in order to enhance the environment, there is a need to reduce the amount of cement used in construction process without influencing either the strength or long-term durability characteristics of concrete. Considerable amount of research work is underway looking at potential of replacement of cement in concrete mix with special types of naturally and locally available ingredients or industrial waste products. It has also been reported by many researchers that concrete produced using alternative supplementary cementitious can be stronger and more durable than conventional concrete made using ordinary Portland cement (OPC). The use of supplementary cementitious materials like fly ash, granulated blast furnace slag, silica fume and activated metakaolin is found to enhance significant properties of fresh and hardened concrete. This initiative supports the global concern of producing environmental friendly materials at lower cost besides solving the disposal problem of these industrial wastes.

Until the advent of nanotechnology, concrete structural enhancement (e.g. concrete rehabilitation and repairs) required adding on the structure besides partial demolition of structure. The nanotechnology has opened broad spectrum of alternative repair strategies like decontamination, permeability reduction and strength gain to remediation from various types of chemical degradation activities. Such advances have also impacted nano science of cementitious materials with increased knowledge and understanding basic phenomena of cement at nano scale such as cohesion in cement, cement hydration, cement structure, concrete interfaces, mechanical characteristics of main hydrate phases, and 
degradation mechanisms. Generally, usage of nanomaterials results in production of concrete with lower volume of cement. The influence of injecting various nano particles such as nano silica, nano $\mathrm{Al}_{2} \mathrm{O}_{3}$, nano $\mathrm{TiO}_{2}$, nano $\mathrm{Fe}_{2} \mathrm{O}_{3}$, nano clays, and highly dispersed carbon nano tubes in concrete is thoroughly investigated in present work with an initiative towards 'Green Concrete' incorporating these waste materials as one of its ingredients.

\section{Carbon Nanotubes}

In Carbon nanotubes (CNT) are considered among major and significant research areas in field of nanotechnology as they are helpful in improving engineering properties of construction materials besides being environmentally sustainable. Advantageous mechanical properties like high strength, ultra-high aspect ratio and elastic behavior and desirable electronic and thermal properties of CNT demonstrate immense potential as reinforcement in concrete. CNT are microscopic molecules which are held together by a very strong bond. They are very small particles (diameter 20$40 \mathrm{~nm}$, length $1-10 \mu \mathrm{m}$, density $0.15-0.35 \mathrm{~g} / \mathrm{cm}^{3}$, surface area $35 \mathrm{~m}^{2} / \mathrm{g}$ ) with carbon purity above $90 \%$ and its typically 100 times stronger than the steel so adding carbon nanotube in any concrete mix can reduce or eliminate the usage of the steel reinforcement [2]. The use of CNT as reinforcing material transfers the macroscopic behavior of reinforcement to nano-scopic level by acting as a filler producing denser concrete, prevent crack growth and propagation at early age, reduce final setting time of concrete and improve quality of bond interaction between cement paste and aggregates.

Madhavi et al. [3] conducted an experimental work to study strength characteristics such as 28-days compressive strength, split tensile strength and water absorption of concrete with varying proportions $(0.015 \%$, $0.03 \%$, and $0.045 \%$ by weight of cement) of multi walled CNT. The number of CNT walls varied from 3-15 while the density of CNT used in the study was $0.15-0.35$ $\mathrm{g} / \mathrm{cm}^{3}$. It is important to evenly disperse and avoid accumulation of multi walled CNT in concrete mix. The study observed water absorption reduction varying from $10.22 \%$ to $17.76 \%$ with increased proportions of CNT. It was also observed that intrinsic pore space created due to hydration and capillary action initially occupied with water were filled with CNT resulting in less porous, more durable and highly stress resistant concrete. A similar behavior of percentage increase was observed for both compressive strength and split tensile strength of concrete with increase in proportion of multi wall CNT. Compressive strength was found to increase by $26.69 \%$ while split tensile strength increased to $66.3 \%$ by adding $0.045 \%$ multi wall CNT. However, the slump value for concrete mix with various proportions of multi wall CNT remained constant.

Tyson et al. [4] in another experimental study added untreated CNT and carbon nano fillers (CNF) as composites to their cement matrix in proportion of 0.1 and $0.2 \%$ by weight of cement to study mechanical properties of concrete such as flexural strength, Young's modulus, ultimate strain capacity and fracture toughness at period of 7, 14 and 28 days. A scanning electron microscope was used in the study to observe difference between crack control and fiber pull-out. For almost all cases, the addition of CNT and CNF resulted in increased peak displacement up to $150 \%$ higher than plain cement paste making it essential for structural applications where higher ductility and strain capacity to failure is demanded. Few other significant characteristics like fracture toughness, flexural strength, Young's modulus and also increased compared to plain cement samples. The average peak stress (i.e., average flexural strength) results are shown in Fig. 1. In many cases flexural strength and Young's modulus were found to reduce after addition of CNT. The study concluded that delay in development of strength, ductility, and toughness along with reduced stiffness were probably because of a shift in bonding between nano filaments and cement matrix. The study recommended further work on the change in microstructural properties so as to fully understand mechanism of delay in bond strength of cement composites.

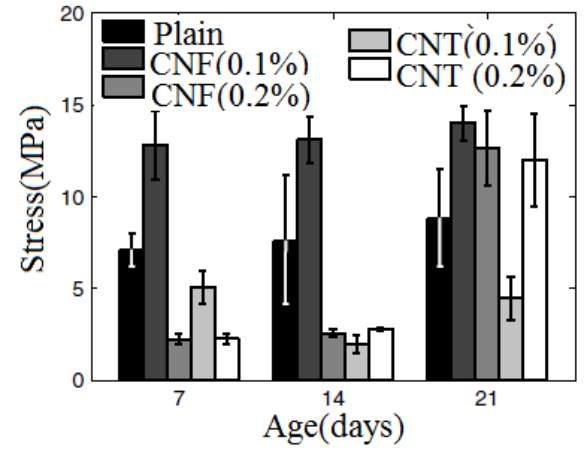

Fig. 1Effect of CNF and multi wall CNT on ultimate strength of concrete [4]

Fig. 2 shows the load vs. displacement response of concrete sample with highest ultimate strength at 7,14 and 28 days respectively from each batch. The study observed highest flexural strength and strain capacity at 28days for CNF samples with $0.2 \%$ by weight of cement.

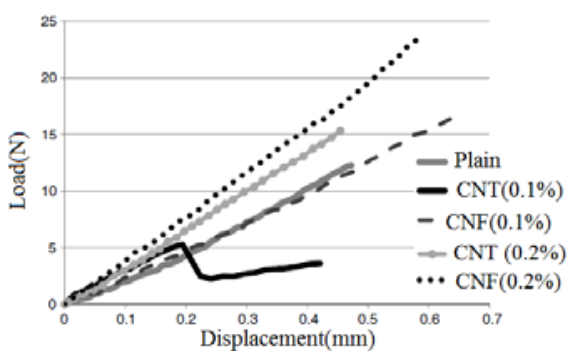

Fig. 2 Load vs. displacement response for highest strength of each sample for 28-day test [4]

Beside the benefits of the CNT in improving desired properties of concrete it also shows some benefits to the environments. As concrete production is responsible of 
more than $5 \%$ of total carbon dioxide emissions worldwide so by adding CNF to the concrete mixture it will reduce the required size of concrete structural members resulting in lesser carbon dioxide emissions making concrete an environmental friendly construction material.

\section{Titanium Dioxide Nano Particles}

Titanium dioxide $\left(\mathrm{TiO}_{2}\right)$ nano particles are another common nanotechnology based materials used in the concrete particularly for the concrete pavements used in road surfaces, parking lots, bridge decks and airfield runways. $\mathrm{TiO}_{2}$ are small particles with typical size of $15 \mathrm{~nm}$, high purity $99.9 \%$, and density less than 0.13 $\mathrm{g} / \mathrm{cm}^{3}$. It has been demonstrated that nano- $\mathrm{TiO}_{2}$ accelerate the early-age hydration of OPC, increase compressive and flexural strengths and improves abrasion resistance of concrete which makes it appropriate for usage in concrete pavements.

Salemi et al. [5] experimentally investigated influence of $\mathrm{TiO}_{2}$ on mechanical properties i.e. compressive strength and durability of concrete by conducting water absorption, freeze and thaw tests and of concrete. This study added $2 \%$ of $\mathrm{TiO}_{2}$ by weight of cementitious materials. An increase in compressive strength of the order $12 \%, 22.71 \%$ and $27 \%$ at 7,28 and 120 days respectively was reported compared to plain cement concrete specimens. The increase in compressive strength of concrete was due to promoted cement hydration as $\mathrm{TiO}_{2}$ has high reactivity by acting as nucleus for cement phases, they also work as nano-reinforcement and thus densify microstructure and interferential transition zone, reduce porosity, and fill pores to increase compressive strength. The study also looked at compressive strength and mass loss, increase in water absorption, and change in length from durability perspective where in concrete specimens were subjected to 50,150 and 300 freezing and thawing cycles.

Inclusion of $\mathrm{TiO}_{2}$ into cement-based material is used in many experimental studies as they have high catalytic activity, more chemical stability and reasonable cost. Fluctuation in test results by various researchers demanded more work in this direction to verify impact of non- $\mathrm{TiO}_{2}$ on cement based mixes before its real application. Zhang et al. [6] used commercially available colloidal nano- $\mathrm{TiO}_{2}$ of length $25 \mathrm{~nm}$ and $30 \mathrm{~nm}$ with varying percentage of $0,1,3$ and $5 \%$ to study characteristics like compressive strength development, overall hydration process and drying shrinkage of concrete. Fig. 3 shows compressive strength determination at 3, 7 and 28days for concrete with watercement ratio of 0.4 . Addition of nano $\mathrm{TiO}_{2}$ increases compressive strength of cementitious material as hydration accelerates and concrete pores are filled with nano $\mathrm{TiO}_{2}$.

Ehsan et al. [7] integrated rice husk ash and nano$\mathrm{TiO}_{2}$ as supplementary cementitious materials in cement mortars in various proportions to study compressive strength, electrical resistivity, water absorption, rapid chloride permeability and ultra-sonic pulse velocity (UPV) besides interfacial transition zone and microstructure of hardened specimens. UPV test results indicate presence of cracks and voids and also estimate effectiveness of crack repairs. This study observed greater values of UPV with increased percentage of nano- $\mathrm{TiO}_{2}$ added to mixtures compared to control samples. High UPV value indicate higher quality and durability of cement based materials.

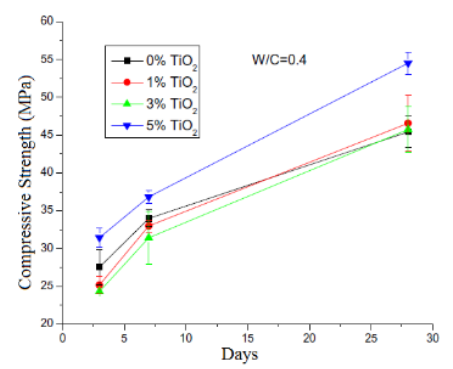

Fig. 3 Compressive strength of nano-TiO2 concrete [6]

Fig. 4 shows UPV values found in comparison to percentage content of nano- $\mathrm{TiO}_{2}$. The results demonstrate that $5 \%$ content of nano- $\mathrm{TiO}_{2}$ is optimal proportion of cement replacement.

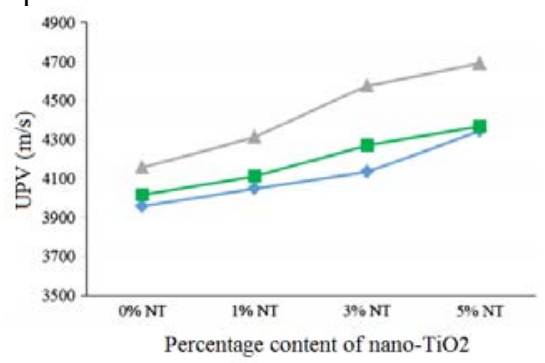

Fig. 4 UPV values of cement mortar for varied percentage content of nano- $\mathrm{TiO}_{2}$ [7]

Moreover, it should also be noted that nano- $\mathrm{TiO}_{2}$ is used in concrete pavements as a coating material because of its special properties of self-cleaning and related environmental benefits like purification of air on sunny days and infiltration of water on rainy days. Nano- $\mathrm{TiO}_{2}$ in concrete pavement also adsorbs the pollution caused by the vehicles; adsorbed pollutant oxidizes under ultraviolet light and afterwards pollutants are washed away by the water. So, by this mechanism both air pollutant caused by the vehicles emission and ground water pollution is reduced.

\section{Nano Silica}

As it is known, the use of cement as an ingredient of concrete contributes to carbon dioxide emissions and thereby to the greenhouse effect. One of the solutions to reduce and minimize that effect is to use nano silica (nS) along with cement. The use of $\mathrm{nS}$ significantly reduces the amount of cement needed as it was reported that addition of $1 \mathrm{~kg}$ of micro-silica permits a reduction of about $4 \mathrm{~kg}$ of cement, and this can be higher if $\mathrm{nS}$ is used 
[8]. This will have significant impact on the environment by reducing the damage induced by $\mathrm{CO}_{2}$ emissions.

The effect of the addition of $\mathrm{nS}$ has both physical and chemical dimensions. On a physical level, the extremely small specific surface (surface area per unit mass) of $\mathrm{nS}$ fills the voids in the hydrated cement paste which accumulates to a higher density and thus results in higher compressive strength. On the other hand, silica reacts with $\mathrm{CH}$ (calcium hydroxide, one of the hydration products of cement) through pozzolanic reaction to produce more $\mathrm{CSH}$ (calcium silicate hydrate) which is another hydration product that is identified as the source of strength gain in concrete.

Durability is another significant mechanical property of concrete. Durability is capability of concrete to sustain the harsh environmental conditions for long periods of time without deterioration. In order to investigate durability of concrete specimen rapid chloride permeability test is usually conducted. Gopinath et al. [9] performed rapid chloride permeability tests on three different types of concrete namely control concrete, nano modified concrete and nano coated concrete to determine chloride permeability and electrical conductance. This study used nano silica gel in order to modify microstructure of normal strength concrete such that its mechanical behavior in compression, tension and flexure could be studied. The study showed nano modified concrete showed higher chloride permeability which implies that it is less durable than normal concrete. However, nano coated concrete which was obtained by immersing normal and nano modified concrete in a nano silica solution for about 12 hours, showed less chloride permeability and hence better durability. This sheds the light on the possibility of using nano silica as a coating material to normal concrete to increase durability.

Another study by Givi et al. [10] studied the size effects of $\mathrm{SiO}_{2}$ (with two sizes $15 \mathrm{~nm}$ and $80 \mathrm{~nm}$ ) nanoparticles on compressive, flexural and tensile strength of binary blended concrete. This experimental study concluded that concrete specimens containing $\mathrm{SiO}_{2}$ particles with average diameter of $15 \mathrm{~nm}$ were stiffer compared to specimens containing $\mathrm{SiO}_{2}$ particles of diameter 80nm during initial days of curing. Jo et al. [11] studied properties of cement mortar with varied proportions of nano-silica and found that nano-size silica in cement mortar acts as a filler and improve microstructure of mortar besides promoting essential pozzolanic reaction.

\section{Nano Alumina (Nano $\mathrm{Al}_{2} \mathrm{O}_{3}$ )}

Another solution to reduce the greenhouse effect induced by the use cement in concrete is to use nanoalumina as partial replacement of cement. Usage of nanoalumina results in formation of C-A-S (calciumaluminum-silicate) gel in concrete by reacting with calcium hydroxide produced from hydration of calcium aluminates. The rate of this reaction directly depends on amount of surface area available. Therefore, it is desired that nano-alumina of high purity and fineness value should be added to enhance characteristics of concrete.
Rao K. and Senthil Kumar [12] studied effect of partial replacement of cement by nano-alumina particles of average diameter $15 \mathrm{~nm}$ in different percentages such as $0.5 \%, 1.0 \%, 1.5 \%$, and $2 \%$ by volume of cement on strength parameters such as compressive strength, split tensile strength and flexural strength experimentally. The study observed compressive strength increase of about $18.42 \%$, split tensile strength increase of about $32.6 \%$, and flexural strength increase of about $44.9 \%$ for mix containing $1.5 \%$ of nano-alumina compared to control mix. Another experimental study by Salemi et al. [5] found that the cement could be advantageously replaced with nano-alumina particles up to maximum limit of $2 \%$ with average particle size of $15 \mathrm{~nm}$ by studying effect of nano particles on frost durability of concrete. In order to determine frost resistance of concrete, the decrease in compressive strength, change in length, loss of mass and increase in water absorption in specimens was measured during the cycles of freezing and thawing. Nanoparticles in concrete mix typically control rate of water absorption increase. In case of plain concrete water absorption increase from $13.4 \%$ to $117 \%$, while for concrete containing nano- $\mathrm{Al}_{2} \mathrm{O}_{3}$ it increased from $6.88 \%$ to $32.11 \%$ as seen in Fig. 5. Enhancement of frost resistance in terms of water absorption can be attributed to consumption of $\mathrm{Ca}(\mathrm{OH})_{2}$ formed during hydration process due to high reactivity of nanoparticles. The hydration of cement is accelerated and large volume of resulting reaction produced are produced.

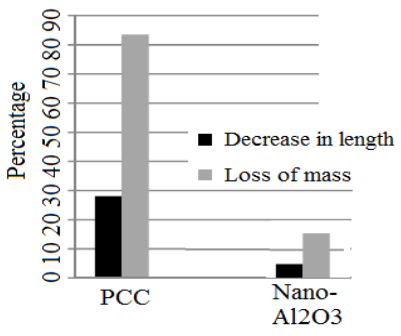

Fig. 5 Decrease in length and loss of mass in concrete specimens during freeze and thaw cycles [5]

Nano-alumina improves compressive and tensile strength of concrete. It also decreases the water absorption and chloride penetration; improving overall durability of concrete. Nazari et al. [13] studied setting time of concrete specimens cast by partial replacing cement by $0.5 \%, 1.0 \%, 1.5 \%$ and $2.0 \%$ by weight with nano-phase $\mathrm{Al}_{2} \mathrm{O}_{3}$ particles of average diameter $15 \mathrm{~nm}$ besides other important mechanical properties. It was found that both initial and final setting time of fresh concrete decreased with increased volume fraction of $\mathrm{Al}_{2} \mathrm{O}_{3}$ nanoparticles as seen in Fig. 6 indicating that nano$\mathrm{Al}_{2} \mathrm{O}_{3}$ speeding up the hydration process compared to plain concrete control specimens as characterized by their unique surface effects, higher surface energy and smaller particles size leading to faster increase in number of surface atoms. These atoms are highly active and unstable resulting in faster hydration. Hence it is necessary that a 
cautious approach for mix design and casting should be followed while utilizing nano- $\mathrm{Al}_{2} \mathrm{O}_{3}$.

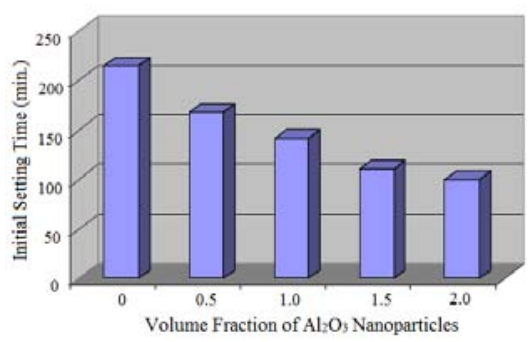

Fig. 6 Decrease in setting time of concrete with increased volume fraction of $\mathrm{Al}_{2} \mathrm{O}_{3}$ nanoparticles [13]

\section{Nano Iron Oxide ( $\left.\mathrm{Nano} \mathrm{Fe}_{2} \mathrm{O}_{3}\right)$}

Inclusion of nano-materials in cement mix to enhance mechanical properties of concrete has emerged as promising research field. Concrete with nano- $\mathrm{Fe}_{2} \mathrm{O}_{3}$ is found to have self-diagnostic ability of stress and improvement of compressive and flexural strengths. This peculiar characteristic of concrete can be used for structural health monitoring in real time without use of any embedded sensors leading to construction of smart and sustainable structures.

Nazari et al. [14] studied effects of incorporation $\mathrm{Fe}_{2} \mathrm{O}_{3}$ nano particles up to maximum replacement level of $2.0 \%$ by volume of cement on tensile and flexural strength of concrete besides setting time (or workability) and found that nano- $\mathrm{Fe}_{2} \mathrm{O}_{3}$ particles blended concrete had significantly higher compressive strength, improved split tensile strength and reduced setting time of fresh concrete compared to conventional concrete. The flexural strength of fresh concrete increased with increase in content of $\mathrm{Fe}_{2} \mathrm{O}_{3}$ nano particles. $\mathrm{Fe}_{2} \mathrm{O}_{3}$ nano particles decrease the total porosity of the concrete, modify the pore structure of cement, mortar and concrete itself and significantly reduced the permeability. This reduces the influence of harmful ions leading to deterioration of the concrete mix. In some other studies addition of Nano- $\mathrm{Fe}_{2} \mathrm{O}_{3}$ and nano$\mathrm{SiO}_{2}$ was found to increase abrasion resistance of concrete used for pavement. Khoshakhlagh et al. [15] worked on high strength self-compacting concrete to study effects of $\mathrm{Fe}_{2} \mathrm{O}_{3}$ nano particles on water permeability and strength assessments. The study conducted several tests on the specimens like compressive, split tensile and flexural strength tests, water permeability tests, mercury intrusion porosimetry to measure the pore structure, conduction calorimetry, thermogravimetric analysis, scanning electron microscopy and X-ray diffraction. It was reported that strength and water permeability measured in terms of coefficient of water absorption improved by adding $\mathrm{Fe}_{2} \mathrm{O}_{3}$ nano particles in the cement paste up to $4 \%$ by weight. The study also proposed some empirical relations to predict flexural and split tensile strength of specimens based on corresponding compressive strength at certain age of curing. Few other observations like accelerated peak appearance in conduction calorimetry tests, more weight loss in thermogravimetric analysis and more rapid appearance of peaks related to hydrated products in X-ray diffraction results indicate that $\mathrm{Fe}_{2} \mathrm{O}_{3}$ nano particles with average particle size of $15 \mathrm{~nm}$ up to $4 \%$ by weight of cement could improve the mechanical and the physical properties of the specimens. Sheikhaleslamzadeh and Raofi [16] investigated effect of nano $\mathrm{Fe}_{2} \mathrm{O}_{3}$ powder particles of spherical, crystalline structure with $99 \%$ purity and average particle size of $60 \mathrm{~nm}$ up to $4 \%$ replacement of cement by weight on fiber reinforced concrete. This experimental work included polypropylene fibers with length of about $6 \mathrm{~mm}$ and density of $0.9 \mathrm{~kg} / \mathrm{m}^{3}$ distributed in different directions. It was found that increasing amount of nano $\mathrm{Fe}_{2} \mathrm{O}_{3}$ particles increase compressive strength of fiber reinforced concrete. However, $2 \%$ nano $\mathrm{Fe}_{2} \mathrm{O}_{3}$ (by weight of cement) have the best effect on the compressive strength of fiber reinforced concrete.

\section{Nano Clays}

Nano clay particles are also used for enhancing mechanical performance, resistance to chloride penetration, self-compacting properties and reducing permeability and shrinkage of concrete. It is well known that ingress of chlorides into concrete initiate corrosion of steel reinforcement and deteriorate concrete member affecting the durability of reinforced concrete. Morsy et al. [18] investigated effect of nano-clay on the mechanical properties such as compressive and tensile strength, phase composition and microstructure of OPC mortar with an intention to constitute a blended cement mortar with high mechanical properties. The study substituted OPC partially with nano-metakaolin (surface area of $48 \mathrm{~m}^{2} / \mathrm{g}$ and average dimensions $200 \times 100 \times 20 \mathrm{~nm}$ ) as $0,2,4,6$ and $8 \%$ by weight of cement. Compressive and tensile strength of the cement mortars with nanometakaolin was observed to be higher than control mortar with same water-binder ratio even at $8 \%$ replacement of cement. The study included variations of the Differential Scanning Calorimetry thermograms nano-metakaolin mortar hydrated for 28 days. The mean features of the thermograms were characterized by a consumption of the peak area and increment in the enthalpy of calciumhydroxide $(\mathrm{CH})$ and an increase of the peak area of few other secondary hydration products such as calcium silicate hydrates $(\mathrm{CSH})$, gehlenite hydrate $\left(\mathrm{C}_{2} \mathrm{ASH}_{8}\right)$ and hydrogarnet $\left(\mathrm{C}_{3} \mathrm{ASH}_{6}\right)$ phases as the nano-metakaolin increases up to $8 \%$ as seen in Fig. 7. Increase in any phase's enthalpy indicates formation of well crystalline phases. Hence, crystallizations produced by nanometakaolin and $\mathrm{CH}$ can fill up mortar pores and enhance microstructure.

Jaafar et al. [18] experimentally studied ability of ultra-high performance concrete to withstand the action of chloride penetration by incorporating nano clay as cement replacement as $1 \%, 3 \%$ and $5 \%$ by weight into ultra-high performance concrete. The results showed that 
incorporating nano clay in concrete mixes causes reduction in workability of mix but marginal increase in compressive strength of ultra-high performance concrete at 28-days compared to mixes without nano clays with optimum value of cement replacement as $3 \%$ by weight. The study recorded highest value of compressive strength as $129.8 \mathrm{MPa}$ with ultra-high performance concrete made using $3 \%$ nano clay due to creation of nano pozzolanic reaction and development of more hydration gel. Moreover, increase in percentage of nano clay resulted in low chloride penetration with increase in age of specimens as nano clays act as ultra-filler material and reduce diffusion coefficient of chloride ion.

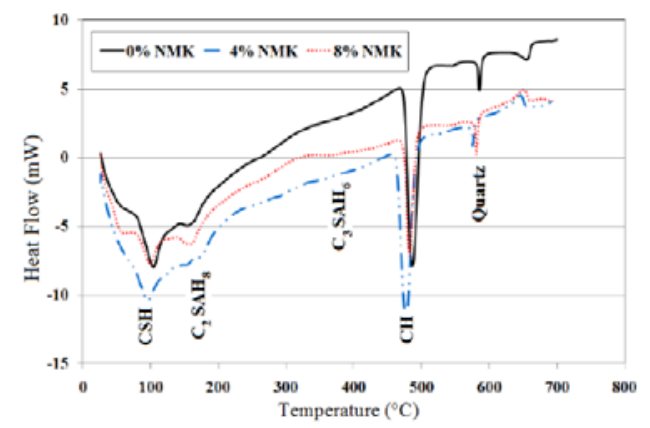

Fig. 7 Differential Scanning Calorimetry thermograms nano-metakaolin mortar hydrated for 28 days [17]

\section{Conclusions}

The impact of implementing nanotechnology into concrete cannot be neglected these days. Concrete being the most widely used construction material across the world, any changes to improve concrete would result in imparting changes to the construction industry globally. Looking for innovative ways to fix reliability issue of concrete by using nanotechnology would lead to safer and more efficient structures, economic savings, and a cleaner environment. The enormous usage and production of concrete makes researchers and engineers constantly look for innovative ways to improve the quality and performance of concrete for specific application. The present study is an attempt to explore utilization of nanoparticles and consequent improvement to concrete characteristics. Moreover, using nano particles technology in the concrete production will make the concrete environmentally sustainable material.

\section{References}

[1] Rubenstein, M. Emissions from the cement industry, Retrieved from URL (2012)

http://blogs.ei.columbia.edu/2012/05/09/emissions-fromthe-cement-industry/

[2] Sasmal, S., Bhuvaneshwari, B., and Iyer, N. Can Carbon Nanotubes Make Wonders in Civil/Structural Engineering? Progress in Nanotechnology and Nanomaterials, Volume 2(4), (2013), pp. 117-129.

[3] Madhavi., T. Ch., Pavithra, P., Singh, S. B., Raj, S. B. and Paul, S. Effect of multi walled carbon nanotubes on mechanical properties of concrete International Journal of Scientific Research (ISSN No. 2277-81179), Volume 2(6), (2013), pp. 166-168.

[4] Tyson, B., M., Abu Al-Rub, R., K., Yazdanbakhsh, A., and Grasley, Z. Carbon nanotubes and carbon nanofibers for enhancing the mechanical properties of nanocomposite cementitious materials Journal of Materials in Civil Engineering, Volume 23 (7), (2011), pp. 1028-1035

[5] Salemi, N., Behfarn, K., and Zaree, S., A., Effect of nanoparticles on frost durability of concrete Asian Journal of Civil Engineering, Volume 15(3), (2014), pp. 411-420.

[6] Zhang, R., Cheng, X., Hou, P., and Ye, Z., Influences of nano- $\mathrm{TiO}_{2}$ on the properties of cement-based materials: Hydration and drying shrinkage Construction and Building Materials, Volume 81, (2015), pp. 35-41.

[7] Ehsan, M., Naseri, F., Amjadi, R., Khotbehsara, M., and Ranjbar, M., Microstructure and durability properties of cement mortars containing nano- $\mathrm{TiO}_{2}$ and rice husk ash Construction and Building Materials, Volume 114, (2016), pp. 656-664.

[8] Maheswaran, S., Bhuvaneshwari, B., Palani, G. S., Nagesh, R., and Kalaiselvam, S., An overview on the Influence of Nano Silica in Concrete and a Research Initiative Research Journal of Recent Sciences (ISSN 2277-2502) Volume 2, (2013), pp.1724.

[9] Gopinath, S., Mouli, P. CH., Murthy, A. R., Iyer, N. R., and Maheswaran, S., Effect of nano silica on mechanical properties and durability of normal strength concrete Archives of Civil Engineering, (2012).

[10] Givi, A. N., Rashid, S. A., Aziz, F. N. A., and Salleh M. A. M., Experimental investigation of the size effects of $\mathrm{SiO}_{2}$ nano-particles on the mechanical properties of binary blended Concrete CompositesPart B: Engineering, Volume 41 (8), (2010), pp. 673-677.

[11] Jo, B.W., Kim, C. H., Tae, G., and Park, J. B., Characteristics of cement mortar with Nano-SiO2 particles Construction and Building Materials, Volume 21(6), (2007), pp. 1351-1355.

[12] Rao, K., and Senthil Kumar, G., An experimental study on strength parameters of nano alumina and GGBS on concrete International Journal for Research in Emerging Science and Technology, Volume 3(4), (2016), pp.14-18.

[13] Nazari, A., Riahi, S., Shirin, R., Seyedeh, F. S., and Khademno A Mechanical properties of cement mortar with $\mathrm{Al}_{2} \mathrm{O}_{3}$ nanoparticles Journal of American Science, Volume 5(7), (2009), pp. 94-97.

[14] Nazari, A., Riahi, S., Shirin, R., Seyedeh, F. S. and Khademno, A., The effects of incorporation $\mathrm{Fe}_{2} \mathrm{O}_{3}$ nano particles on tensile and flexural strength of concrete Journal of American Science, Volume 6(4), (2010), pp.90- 93.

[15] Khoshakhlagh, A., Nazari, A., and Khalaj, G., Effects of incorporation $\mathrm{Fe}_{2} \mathrm{O}_{3}$ nano particles on 
water permeability and strength assessments of high strength self-compacting concrete Journal of Material Science Technology, Volume 28(1), (2012) pp. 73-82

[16] Sheikhaleslamzadeh, S., M., and Raofi, M., Effect of nano $\mathrm{Fe}_{2} \mathrm{O}_{3}$ on the fiber reinforced concrete Research Journal of Applied Sciences Engineering and Technology, Volume 13(10), (2016), pp.781-783.

[17] Morsy, M., S., Alsayed, S., H., and Aqel, M., Effect of nano-clay on mechanical properties and microstructure of ordinary portland cement mortar International Journal of Civil and Environmental Engineering, Volume 10(1), (2010), pp. 21-25.

[18] Jaafar, M., Faizal, S. H., Sidek, M., Norhasri, M., Noorli, P., Chloride permeability of nano clayed ultra-high performance concrete, International Civil and Infrastructure Engineering Conference, (2015), pp.613-623. 